\title{
Innovation in education: the social representations and practices of greek teachers
}

\begin{abstract}
This paper aims at highlighting Greek teachers' social representations and practices with regard to innovation, and, most notably, innovation concerning matters of the curriculum. The starting point for this research was our personal involvement as teaching staff in various programs in school. Moreover, our conviction is that now-adays the notion of innovation is even held, in the official discourse, as the keystone for the development of a country and so the term has already acquired a rather normative sense and as such acts in a performative way.
\end{abstract}

Keywords: greek teachers, social representations, innovation, community, economy of learning, education, international organizations, government, entrepreneurs, educators, social scientists, health education, environmental education, olympic education, school career orientation
Volume I Issue 4 - 2017

\author{
Pandelis Kiprianos and Nikolaos \\ Theodoropoulos \\ Department of Educational Science and Early Childhood \\ Education, University of Patras, Greece
}

Correspondence: Pandelis Kiprianos, Department of Educational Science and Early Childhood Education, University of Patras, Greece, Email: kiprian@upatras.gr

Received: July 20, 2017 | Published: November 13, 2017

\section{Introduction}

In particular, we study Greek teachers because in Europe the subject of innovation has been widely debated and we want to examine this issue in Greece as well because there are not many relevant studies. Apart from the use of the notion of innovation, two others factors have led us to this investigation. Despite some effort being made towards decentralization, education in Greece still remains centralized and leaves limited room for the members of the school community, foremost the teachers, to act independently. On the other hand, the discourse of the authorities as well as of many scholars holds the notion of innovation as the medium par excellence for overcoming all the problems and the difficulties the school faces. To this end, we will consider first the notion of innovation and then as it actually applies to education. We will then move on to a review of the field of related research, pose our research questions, clarify our theoretical framework and our research, and conclude with an analysis of the teachers' responses.

\section{On the notion of innovation}

The term innovation derives from economic theory. It is a fundamental term in Joseph Schumpeter's work who considered it to be embedded in the entrepreneur, who in order to survive and expand his business, did not have any choice but innovation. Therefore, innovation was the prerequisite for the survival of capitalism and its ongoing development. Over the last few years the concept of innovation has penetrated many scientific fields, including education. Nowadays, the role of education is debatable in a rapidly changing world. Many, including international organizations, governments, entrepreneurs, educators and social scientists, argue that education should be a pillar of social evolution. Therefore, they go on, it is essential that education reconsider the facts and develop innovations that will respond to the changing society. ${ }^{1}$

\section{As noted by OECD}

We are moving towards an 'economy of learning' in which the success of individuals, organizations, regions and countries reflects more than anything else their ability to learn. ${ }^{2}$ At the meeting of the Ministers of OECD, held in 2000, on the nature of the new tools in educational policy, it is stated that: The schools are creations of the industrial society and they need to change. The successful economies will be based on three cornerstones: the ability to be creative, to transform a creative idea into an innovation and promote it effectively to the market. In 'the economies of knowledge', people are involved in lifelong education since their knowledge and skills should be constantly refreshed. It is necessary that people become able to exploit their creative or innovative abilities in unstable environments, where knowledge is changing and renewed rapidly. They must become aware of learning in a more independent way. ${ }^{2}$

According to the OECD, innovation is the transformation of an idea into a marketable product, a functional method of production or distribution, or even a new method of providing social services. On the other hand, when the term innovation denotes a new product, equipment, or service successfully diffused into the market, the emphasis is on the outcome of the process. In the first case, innovation refers to a system of interactions between the different parts involved, whose experience, knowledge and expertise are enhanced and enriched. Regarding the second case (innovation as a result), we distinguish radical from improving innovation which transforms products or services with progressive improvements. The emergence of the new products or services can take place in all sectors. ${ }^{3}$

All the above suggest that the economy of modern societies is based on knowledge but mainly on the human ability to expand, enrich, and constantly improve this knowledge. As for the educational system, according to Hargreaves: ${ }^{1}$ An advanced 'economy of knowledge' needs an educational system created by the state, which will not only release but provide a major boost to the economy as well. As stated by House, ${ }^{4}$ innovation is the intentional systematic effort to change schools through new ideas and techniques which further aim at improving specific aspects of the school reality. Additionally, the school reality today presents intense examples of standardization and routine since both the process of providing knowledge and the socialization of students have been subject to the syllabus and the demands of the examinations. To sum up the aforementioned remarks, innovation is held to be crucial for a social system and even more so for an educational system for three reasons: 
i. It opens new horizons for the development of the economy

ii. It renews school routine

iii. It improves the function of the school innovation

As for the content of the notion, three criteria are invoked:

i. The first criterion is the conception of ideas by the members of an organization themselves. In order for an initiative to be characterized as innovative, it must be derived from its executives. So, borrowing ideas does not constitute an innovation.

ii. The second criterion is to be pioneering in the application of ideas. An organization is considered to be innovative when it is a pioneer in the application of an idea.

iii. The third criterion that determines innovation is the number of new ideas.

\section{Innovation in the field of education: dilemmas and questions}

It is a common knowledge that societies as well as institutions change over the course of time. Thus, the most significant questions are related to the rapidity of these changes, as well as their direction and their content. A few decades ago, political scientists were actively involved in research related to the way the under-developed countries of the so-called third world will evolve and become modernized. Nowadays, similar research focuses on different levels of the educational system and how education could contribute to the development of a country and to the country's economy in particular. The relations between education and the economy strongly concern international organizations, but this issue will not be further discussed here. Instead, we will focus on two main aspects, one psycho educational and one sociological. Jerome Brunner reminds us how complex the educational aims are and how arduous their selection is as well as their implementation. This issue is not new and it is obviously quite complex. It is also related to two main aspects, one being the particular image of the various social groups and classes in a society which is linked to different interests and values. Another aspect is related to what Max Weber called polytheism of values, i.e., the right of every individual and every group of people to expect that their right to differentiation is fully respected.

More specifically, Bruner notes. As in most revolutionary times, our times are caught up in contradictions. Indeed, on closer scrutiny, contradictions in such times often turn out to be antinomies pairs of large truths, which, through both may be true, nonetheless contradict each other. Antinomies provide fruitful grounds not only for strife, but also for reflection. For they remind us that truths do not exist independently of the perspectives of those who hold them to be so. ${ }^{5}$ Under this perspective Bruner sets out three of the most baffling of these antinomies. We mention only the first of these antinomies for it relates closely to the notion of innovation.

The first antinomy, notes Bruner, is this: on the one hand, it is unquestionably the function of education to enable people, individual human beings, to operate at their fullest potential, to equip them with the tools and the sense of opportunity to use their wits, skills, and passions to the fullest. The antinomic counterpart to this is that the function of education is not only to reproduce the culture that supports it, but further its economic, political, and cultural ends. ${ }^{5}$ If Brunner is right, the question is where do we need to target innovation? In the direction of the first target or the second? Even if we choose both, overlooking its contradictions, it is still not clear which goal is the most important. Supposing we evaluate and rank them again, the problem will not be solved since the issue of balance between delivery and change as well as individual and collective goals will always be raised.

These difficulties are associated with the second aspect, which is sociological. It is obvious that no individual or organization remains stagnant, on the contrary, they are constantly evolving. This general conclusion does not negate the existence of sociological parameters, though. From this point of view, Pierre Bourdieu examined two concepts, those of Habitus and of the Field that allow us to understand and interpret individual and collective practices. ${ }^{6,7}$ The concept of habitus provides an insight into the trajectory of an agent and into the constraints and limitations that are placed on individual and collective action. In short, change or in this case innovation is linked to the groups and people we are referring to. This means that we cannot understand individual and collective practices unless we have an insight into the capital and the individual trajectories of the people we are studying.

The second concept of field has two aspects, internal and external. The first relates to the structuration of the field, which means the relationship of the agents who constitute it. The second, the external one, concerns the relationship of this field with other fields and with authority, whether this is political, economic or intellectual. Therefore, so as to continue on the topic discussed which is the uptake of innovation by Greek teachers and the practices that they develop on the issue, we need to understand not only their viewpoint and their background, but also the structure of the educational field and its internal relationships, as well as the relationship between education and the authorities.

\section{The introduction of innovations in the greek educational system}

From the rather limited number of studies available on innovation in Greek education, it can be deduced that innovations are not easily accepted and only some of them are implemented. The policy of innovations is sidelined and its contribution to the improvement of the educational unit is underestimated. ${ }^{8}$ Even though certain attempts have been made in order to introduce innovations in schools, the nature of the educational system practically cancels such efforts out since it does not allow teachers to develop and undertake initiatives. Furthermore, the curricula and their adherence to traditional ways of learning do not give the teachers the opportunity to familiarize themselves with new educational practices that call for innovative actions. Finally, the unclear setting of responsibilities in educational action as well as the lack of a coordinating centre on innovation demotivates teachers from being involved in the process of introducing innovations. ${ }^{8}$ The teachers who have not acquired sufficient scientific, teaching and pedagogical training in their initial learning even face difficulties in classroom management. The educational support they receive from the competent institutions is considered to be incomplete and is not addressed to all teachers. Therefore, it seems that the latter are unable to cope with the increasing demands of their role or deal with cases of uncertainty caused by the introduction and application of innovative programs. ${ }^{9}$

Consequently, any innovation introduced remains pending and impractical in essence. So, it is easy to understand the reason why teachers and headmasters tend to choose the kind of innovations 
mostly related either to teaching issues, such as Learning Support (or Supplementary Teaching Support) or non-teaching related programs, like Health Education, Environmental Education, Olympic Education, and School Career Orientation. Common are the innovations implemented as cultural events as well (like theatre, choir, traditional dances, library, photography exhibition and sports competitions), in which schools show special interest. On the contrary, less common are such innovations as a Free Hour for innovative actions or a SEPPE Program (Schools of Experimental Application of Education Programs), that require changes in the whole school timetable and the function of the school in general. ${ }^{10}$

\section{The research:approach and questions}

Our purpose is to investigate the social representations and practices of Primary Education teachers in an area of western Greece, regarding the notion of innovation. We use the concept of social representations as elaborated and used by the French social psychologist Serge Moscovici. ${ }^{11}$ Inspired by the approach of Georg Simmel who emphasizes interaction, Moscovici ${ }^{11}$ borrows the term "representation" from Emile Durkheim, but he defines it as a concept, not as a phenomenon. Thus, the concept acquires a dynamic connotation, for the emphasis is put on individual and collective interaction. According to Moscovici "To sum up: if, in the classic sense, collective representations are an explanatory device, and refer to a general class of ideas and beliefs (science, myth, religion, etc.), for us they are phenomena which need to be described and to be explained. They are specific phenomena which are related to a particular mode of understanding and of communicating a mode which creates both reality and common sense. It is in order to stress such a distinction that I use the term 'social' instead of 'collective'."1

Departing from Moscovici's approach, the research investigates the following three questions:

a. What are the teachers' social representations on the notion of innovation and what features do they attribute to it?

b. To what extent do they innovate?

c. What are the factors that affect the introduction of innovations in school?

As a means of collecting the data we used a questionnaire which included (6) questions on the teachers' profile and another (24) related to the two research questions of the study. The questionnaire was the result of initial semi-structured interviews and of a pilot application to nineteen (19) teachers in order to check both the validity of its content and the structure of its questions. The collection of data took place from March 2011 and was completed in late April 2011.

All the active primary school teachers in the study area during the school year from 2010 to 2011 were defined as the research population. 129 teachers from the study area were included in the final sample. Their selection for each sub-area of study (urban, suburban, and rural) was accomplished through the method of simple random sampling, according to which each unit of the population has exactly the same chance of being included in the sample. In this case, the choice of the subjects of the research was random. More specifically, subjects from all the three different geographical regions (rural, urban, and suburban) of the study area were included in the sample of the teachers. So, the final research sample-consisted of 129 persons in total which represents $13.78 \%$ of the 935 teachers in the area. Of those 129 teachers, 64 are men and 65 women. We should point out here that it is difficult, based only on the questionnaire, to delve more deeply into the teachers' social representations. For this purpose, and in accord with Moscovici's approach, it would be useful for us to know as much their background and their trajectories, as their interaction with one another within the space of the school. Despite these restrictions, our research allows us to form a picture of how the teachers represent the concept of innovation and how they act in this area.

\section{The social representations of the teachers}

The first question is on the representation of the notion of innovation. The teachers were invited to answer two questions, one of an open type, the other closed. In the first they are asked what they believe innovation to be. 44.3 of the respondents perceive innovation as "a new method-approach to teaching", $38.6 \%$ perceive it as "something new modifying the status quo", and $17 \%$ as "the systematic use of Information Communication Technologies (ICTs) in the classroom".

Beyond the content of the responses, the number of responses to this open question is also of interest. Of the 129 who were questioned, only 88 answered, of which 58 were men and just 30 women. In other words, while a relatively small number of men (8) do not answer, fewer than half the women answer. Is it a matter of choice or awkwardness? We suspect the latter since many more go on to answer when the questions posed are less abstract and closer to their everyday life. We could suppose that here we have to do with a common practice, that is to say, men, for reasons to do with their stronger presence and their taking on of positions of responsibility, more easily express opinions on public matters. Indeed, immediately afterwards the teachers were asked which of the 9 cited items they consider innovative. All the men and women who were asked, answered this question, which concerns particular educational programs that are implemented in all Greek schools and so consequently more or less all teachers are aware of them. This means that, as we already know, we have a tendency to answer more easily on matters that we know about and even more soon those we have experienced. As for the answers to the question, these are almost equally distributed between the 7 items. "The new methods of teaching" (19.2\%) and "environmental education" (14.7\%) stand out slightly (Table 1).

Table I What do you believe are, in general, the benefits of the implementation of an innovation in school

\begin{tabular}{|c|c|c|c|c|c|c|}
\hline & \multicolumn{2}{|c|}{ Men } & \multicolumn{2}{|c|}{ Women } & \multicolumn{2}{|c|}{ Total } \\
\hline & f & $\%$ & f & $\%$ & f & $\%$ \\
\hline Better student performance & 3 & 15 & 17 & 85 & 20 & 15.5 \\
\hline Smoother pupil integration into the educational process & 19 & 73.1 & 7 & 26.9 & 26 & 20.2 \\
\hline Positive attitude of the pupils towards school & 19 & 65.5 & 10 & 34.5 & 29 & 22.5 \\
\hline A climate of cooperation between the teachers and the head teacher & - & - & 8 & 100 & 8 & 6.2 \\
\hline
\end{tabular}


Table Continued....

\begin{tabular}{|c|c|c|c|c|c|c|}
\hline & \multicolumn{2}{|c|}{ Men } & \multicolumn{2}{|c|}{ Women } & \multicolumn{2}{|c|}{ Total } \\
\hline & $\mathbf{f}$ & $\%$ & $\mathbf{f}$ & $\%$ & f & $\%$ \\
\hline Development of initiatives by the teachers & 5 & 31.2 & 11 & 68.8 & 16 & 12.4 \\
\hline Improvement of school infrastructure & 13 & 61.9 & 8 & 38.1 & 21 & 16.2 \\
\hline Stronger presence of the school in the local community & 5 & 55.6 & 4 & 44.4 & 9 & 7 \\
\hline Total & 64 & 49.6 & 65 & 50.4 & 129 & 100 \\
\hline
\end{tabular}

Frequency $=(f)$; Pearson Chi-Square $(x 2)=29.6$; Degrees of freedom $(d f)=6$; Significant $(2$-sided $)(P)=<0.05$

The second question concerns the degree of acceptance of innovation. For this reason we posed the open question of whether "innovations should be introduced into the schools". This question was answered by 58 of the 64 male teachers and by 60 of the 65 female teachers. Percentage $94.8 \%$ of men answered in the affirmative and $5.8 \%$ negatively. The respective percentages for the women were $86.7 \%$ and $13.3 \%$. Beyond the relatively small differences in gender we can say that the vast majority of those questioned, a little more than $80 \%$ if we also count those who didn't answer, see innovation in positive terms. To delve more deeply into the issue of the representation of innovation we posed a question connected to the previous one. We asked them why they believed that innovation is important for the school and education. For that reason we asked them a closed type question which included seven items which focused on three topics: improvement of the pupils' investment in the school, improvement of the relationship between the teachers and the pupils and the teachers and their colleagues, and thirdly, the better relationship of the school with society and the environment.

We note that all those questioned provided an answer to this closed question. As far as their responses are concerned, these focus chiefly on the improvement of the image of the school in the eyes of the pupils and consequently the improvement of their performance. Secondly, they believe that the introduction of innovations will bring dual benefits for the operation of the school; in the improvement of the infrastructure of the school and in the "development of innovations on the part of the teachers". It is worth noticing here too the divergence between the responses of the men and the women. The women place greater emphasis on the power relations and the relationship of the school with the community, a fact which may be connected to their smaller participation in school administration and their greater sensitivity to issues outside the school such as probably the relationship with the family or cultural matters.

If, as would appear from the answers, innovation is of such vital significance not only for the cognitive progression of the child, the next series of questions were related to the teachers' practices. We asked them if they believed that they have implemented innovative programs in their school and then, if yes, why they did so. As far as the first question is concerned, the implementation of innovations, all those questioned responded, with the exception of one. As for content, more than half $(57.8 \%)$ stated that they had implemented innovations, and fewer $(42.2 \%)$ that they hadn't. Here it is worth noting that the percentages are exactly the same for the men and the women. In the related question concerning the reasons behind their non-involvement, the teachers mentioned mainly $(37 \%)$ the lack of time.

But why did they become involved in the implementation of innovations? As is apparent in the (Table 2), incentives dominate the teachers' discourse: firstly the improvement of the educational work and secondly personal satisfaction. We could safely point out here the divergence in the women's and the men's discourse since the former give greater weight to personal satisfaction and monetary incentives while the latter to the improvement of the educational work (Table 2). In any case, it differs to note two things. These are the teachers' positive attitude towards the implementation of innovations and their belief that they do this for the children first and for themselves and their personal satisfaction second. Both of these observations can lead us to suppositions regarding the teachers' picture of the child and the school firstly and their work secondly. In other words the implementation of innovations helps them make their work more enjoyable and less monotonous, while at the same time however their willingness to participate so that their educational work can become better for the benefit of the institution and of course the school also counts.

Table 2 For what reasons would you participate in the implementation of an innovation

\begin{tabular}{llllllll}
\hline & \multicolumn{3}{c}{ Men } & \multicolumn{3}{c}{ Women } & \multicolumn{3}{c}{ Total } \\
\cline { 2 - 8 } & $\mathbf{f}$ & $\%$ & $\mathbf{f}$ & $\%$ & $\mathbf{f}$ & $\%$ \\
\hline Personal satisfaction & 17 & 43.6 & 22 & 56.4 & 39 & 30.2 \\
Improvement of the educational work & 35 & 58.3 & 25 & 41.7 & 60 & 46,5 \\
Monetary incentives & 4 & 28.6 & 10 & 71.4 & 14 & 10,9 \\
Supplementation of mandatory working hours & 3 & 50 & 3 & 50 & 6 & 4,7 \\
By request of the head teacher & 2 & 66.7 & 1 & 33.3 & 3 & 2,3 \\
Possibility of professional advancement & 3 & 42.9 & 4 & 57.1 & 7 & 5,4 \\
Total & 64 & 49.6 & 65 & 50.4 & 129 & 100 \\
\hline
\end{tabular}

Frequency $=(f)$; Pearson Chi-Square $(x 2)=5.3$; Degrees of freedom $(d f)=5$; Significant $(2$-sided $)(P)=<0.05$ 
But how do the teachers come to implement innovations? Ultimately, what does the introduction and implementation of innovations depend on? To investigate this matter, we posed three related questions. The first concerned the difficulties the teachers encountered during the implementation, the factors that, in their opinion, influenced the introduction of innovations and, finally, who they consider responsible for deciding on the introduction of innovations. As far as the first question is concerned, all the teachers except two answered. They state that the chief difficulties concern the unsuitability of the infrastructure, financial difficulties and their own inadequate training on the matter. Noteworthy here too are the divergences between the answers of the men and the women. The men focus more on the economic obstacles while the women on the inadequate training and mainly on the unsuitability of the infrastructure. The divergence could be related to the fact that men hold the position of head teacher and deputy head to a far greater extent and from these positions they are more involved in financial management (Table 3).

Table 3 What are the problems that come up in your school unit during the implementation of innovations

\begin{tabular}{lllllll}
\hline & \multicolumn{2}{c}{ Men } & \multicolumn{2}{c}{ Women } & \multicolumn{3}{c}{ Total } \\
\cline { 2 - 7 } & $\mathbf{f}$ & $\%$ & $\mathbf{f}$ & $\%$ & $\mathbf{f}$ & $\%$ \\
\hline Unsuitable infrastructure & 8 & 25 & 24 & 75 & 32 & 25.2 \\
Financial difficulties & 29 & 72.5 & 11 & 27.5 & 40 & 31.5 \\
Inadequate teacher training on matters of innovation & 13 & 68.4 & 6 & 31.6 & 19 & 15 \\
Complexity of the innovation & 6 & 50 & 6 & 50 & 12 & 9.4 \\
Insufficient support from the head teacher and colleagues & 7 & 100 & - & - & 7 & 5.5 \\
Lack of support from parents and local bodies & - & - & 17 & 100 & 17 & 13.4 \\
Total & 63 & 49.6 & 64 & 50.4 & 127 & 100 \\
\hline
\end{tabular}

Frequency $=(f)$; Pearson Chi-Square $(x 2)=42.6$; Degrees of freedom $(d f)=5$; Significant $(2$-sided $)(P)=<0.05$

As far as the introduction of innovations is concerned, according to the answers of the teachers, several factors affect their introduction at school. The factors that may make possible the implementation of innovative activity are the substantial teacher training on appropriate pedagogical practices, the reform of syllabuses and curricula, the introduction of cross-curricular projects in the curriculum, and the improvement of the infrastructure. In addition, the teachers consider the role of the school headmaster crucial in the implementation of a successful innovation. He should plan, assign roles, encourage the teaching staff, inform them about it, take part in the implementation stage, and get in contact with all the stakeholders. And who, ultimately, according to the teachers, should be responsible for the introduction of innovations into the school? More than half the teachers believe that innovations should be designed within the school. Percentage $24.2 \%$ believes that it should be the teachers themselves, $9.7 \%$ the head teachers of the schools and $17.7 \%$ the school advisors. A significant percentage approaching $40 \%$ believes that they should be designed by "specialists" which means the Pedagogical Institute, the Universities or the competent research bodies. Finally, $9.7 \%$ of the teachers who responded believe that the introduction of innovations falls within the competence of the Parent's Association (Table 4).

Table 4 Who do you believe should design an innovative action

\begin{tabular}{llllllll}
\hline & Men & \multicolumn{3}{l}{ Women } & \multicolumn{3}{c}{ Total } \\
\cline { 2 - 8 } & f & $\%$ & f & $\%$ & f & $\%$ \\
\hline Pedagogical Institute & 15 & 78.9 & 4 & 21.1 & 19 & 15.3 \\
University & II & 84.6 & 2 & 15.4 & 13 & 10.5 \\
Research Centres & 3 & 18.8 & 13 & 81.3 & 16 & 12.9 \\
School Advisors & II & 50 & 11 & 50 & 22 & 17.7 \\
Schools' head teachers & 7 & 58.3 & 5 & 41.7 & 12 & 9.7 \\
Teachers & 13 & 43.3 & 17 & 56.7 & 30 & 24.2 \\
Parent's and Guardians' Association & 4 & 33.3 & 8 & 66.7 & 12 & 9.7 \\
Total & 64 & 51.6 & 60 & 48.4 & 124 & 100
\end{tabular}

Frequency $=(\mathrm{f})$; Pearson Chi-Square $(x 2)=20.9$; Degrees of freedom $(d f)=6$; Significant $(2$-sided $)(P)=<0.05$

We should note at this point to the divergences between the answers of the women and the men. The former attach greater weight to bodies within the educational community and especially the teachers and the parents. In any case, from the related answers we can observe that the majority of the teachers believe that the introduction of innovation is more the responsibility of the teachers themselves and the local education executives and less the responsibility of specialists such as the research centers, the universities and the pedagogical institute. Many teachers are confined to the management of everyday life in school and don't search out innovative ideas, in teaching or in other domains. This attitude, which is in contrast with what they say, may be attributed to the traditional centralism of the Greek educational 
system, ${ }^{12}$ despite the steps taken towards creating a more decentralized system. ${ }^{13,14}$ As many decisions have been planned by the central administrative bodies, the head teacher and the teachers are often left wondering whether they are entitled to act in compliance with the official educational policy. ${ }^{15-18}$

\section{Conclusion}

At the outset of this research we supposed that because of their background and the traditional centralism of the Greek educational system as well the teachers in our sample would be uncomfortable with or even negative towards innovation and that they wouldn't take related initiatives. The results were quite different. ${ }^{19,20}$ From the answers of the teachers in our sample, we can make two statements. Innovation for them seems to be something obvious and vital for the functioning of the school. Consequently, they declare their willingness to participate in innovative programs either for their personal satisfaction or in order to improve their educational work. On the other hand, their representation of the notion of innovation is a little vague and limited to precise educational activities. This is depicted in the noteworthy divergence of the teachers who answer the open and closed questions. ${ }^{21}$

However, the teachers do not act accordingly, as they are more confined to the implementation of the official educational policies and to the management of the daily school routine. The teachers ascribe it to external factors such as the centralized character of the education system and the lack of the appropriate logistics which obliges them to deploy more time and more energy for their design and implementation. The discrepancy between discourse and action does not apply only to Greek teachers. Insufficient teacher training together with the complexity of the educational aims and problems make them doubt their abilities. In order to meet the challenges and not spoil their image, teachers resort to traditional methods or avoid getting involved with innovation altogether. Their refusal often becomes more intense out of fear of a heavier workload and that seems, like in other countries, ${ }^{22,23}$ to be directly connected to their years of experience). In any case this is perhaps the most interesting aspect from the point of view of the drawing up of educational policy, since most teachers believe that innovations should be designed and implemented by members of the educational community and not at a distance from the school, by politicians or "specialists".

\section{Acknowledgements}

None.

\section{Conflict of interes}

The author declares no conflict of interest.

\section{References}

1. Hargreaves A. Teaching in the Knowledge Society, Education in the Age of Insecurity. USA: Teachers College Press; 2003. p. 1-241.

2. OECD. Knowledge and skills for life: First results from PISA 2000. Organization for Economic Co-operation and Development, Paris, France; 2001. p. 1-24.
3. OECD. The knowledge-based economy. A set of facts and figures. France: OECD; 1999. p. 1-46.

4. House ER. Technology versus craft: a ten year perspective on innovation. Journal of Curriculum Studies. 1979;11(1):137-151.

5. Bruner JS. The Culture of Education. USA: Harvard University Press; 1996. $240 \mathrm{p}$.

6. Bourdieu P. Le sens pratique. France: Minuit; 1980. p. 1-480.

7. Bourdieu P. Raisons pratiques. Sur la théorie de l'action. France: Seuil; 1994. $256 \mathrm{p}$.

8. Mavroskoufis D. The introduction and reception of innovations in schools: theoretical framework and practical problems. Nea Paideia. 2002;103:16-23.

9. Chatzidimou D, Stravakou P. Peripheral Education Centers as institutionalized centers of training and their contribution to teaching. Greece: Kiriakidi editions; 2005.

10. Anagnostopoulou M. Trends in search of the effective teacher. USA: Educational Issues; 2001. p. 61-62.

11. Moscovici S, Duveen G. Social representations. UK: Polity Press; 2000. p. 1-77.

12. Iliou M. The role of research in the process of educational changes. Deltio Eterias Neoellinikou Politismou \& Genikis Pedias. 1982;5:24-35.

13. Brine J. Educational and Vocational Policy and Construction of the European Union. International Studies in Sociology of Education. 1995;5(2):145-163.

14. Dewey J. The Child and the Curriculum. USA: The Chicago University Press; 1902. p. 1-31.

15. Kiprianos P. A Comparative History of Greek Education. Greece: Vivliorama; 2004.

16. Ryba R. Toward a European Dimension in Education: intention and reality in European Community policy and practice. Comparative Education Review. 1992;36(1):10-24.

17. Ryba R. Developing the European Dimension in Education: the roles of the European Union and the Council of Europe. In: Sherman Swing E, et al. editors. Problems and Prospects in European Education. UK: Praeger; 2000. p. 244-261.

18. Sergiovanni TH. Leadership: What's in it for schools? UK: Routledge and Falmer; 2001.

19. Vandenberghe J, Van Huissteden J. Fluvio-eolian interaction in a region of continuous permafrost: Proc. Vth International Conf. on Permafrost. Trondheim, Norway; 1988. p. 876-881.

20. Vandenberghe R. School improvement from a European perspective. Qualitative Studies in Education. 1988;1(1):79-90.

21. Weindling D. The Process of School Improvement: some practical messages from research. School Organization. 1989;9(1):53-64.

22. Ryan T, Joong P. Teachers and Students Perception of the Nature and Impact of Large-Scale Reforms. Canadian Journal of Educational and Administration Policy. 2005;38:42-50.

23. Hinde ER. School Culture and Change: an examination of the effects of school culture on the process of change. USA: Arizona State University West; 2004. p. 1-2. 